Original article

\title{
Methodology of designing specialized medical information registries
}

\author{
Aleksander S. Fedonnikov ${ }^{1}$, Anna S. Kolesnikova ${ }^{2}$, Yuliya Yu. Rozhkova ${ }^{1}$, Irina V. Kirillova ${ }^{2}$, \\ Leonid V. Bessonov², Vladimir Yu. Ulyanov' ${ }^{1}$, Leonid Yu. Kossovich ${ }^{2}$ \\ ${ }^{1}$ Saratov State Medical University, Saratov, Russia \\ ${ }^{2}$ Saratov State University, Saratov, Russia
}

Received 2 August, 2018, Accepted 21 January, 2020

Original Text (C) Fedonnikov A.S., Kolesnikova A.S., Rozhkova Yu.Yu., Kirillova I.V., Bessonov L.V., Ulyanov V.Yu., Kossovich L.Yu., 2018, published in Saratov Journal of Medical Scientific Research 2018; 14(3): 434-437.

(C) 2020, Fedonnikov A.S., Kolesnikova A.S., Rozhkova Yu.Yu., Kirillova I.V., Bessonov L.V., Ulyanov V.Yu., Kossovich L.Yu.

(C) 2020, Saratov Medical Journal

\begin{abstract}
:
The objective. Developing information exchange methodology by means of specialized registries among the core healthcare partakers in the course of provisioning medical assistance to traumatology and orthopedic patients.

Materials and Methods. We conducted the analysis and systematization of functionality for 31 registers of traumatology- and orthopedics-related medical information from the databases of the Federal Institute of Industrial Property, European Patent Office and developers' websites. The search depth has been set at 1979 and defined by the date of the earliest discovered information source.

Results. The analysis of specialized registries revealed that majority of those (70.9\%) were mono-nosologic, hence containing information about the diagnosis and treatment procedures provided at the level of a specific medical institution. We developed the methodology for evaluating the functionality of specialized medical information registries, containing the data on used medical devices, medications, medical technologies, rehabilitation programs, and assessment of medical treatment effectiveness. Such methodology was designed to operate on data from the information systems of major healthcare partakers.

Conclusion. The proposed information exchange methodology defined the necessity of integrated, target-oriented registry development. Its implementation would allow increasing the quality of management decisions proposed by healthcare participants.
\end{abstract}

Keywords: patient registry, registry design, medical information, healthcare management.

Cite as Fedonnikov AS, Kolesnikova AS, Rozhkova YuYu, Kirillova I.V., Bessonov L.V., Ulyanov V.Yu., L.Yu Kossovich. Methodology of designing specialized medical information registries. Saratov Medical Journal 2020; 1(1): e0103

Correspondence to Aleksander S. Fedonnikov. Tel.: +7(900)3141399. E-mail: fedonnikov@mail.ru

\section{Introduction}

The needs of a healthcare as a social system are associated with progressive improvement of the medical, social and economic efficiencies, along with the safety of medical activity, standardization of provided services, procedures and anticipated healthcare results. One of the tools for resolving these issues is represented by the patient registries, classified into the following three categories: registries of pharmaceutical products and medical equipment, disease registries (mono- and poly-nosologic registries), and healthcare delivery registries (including clinical registries) [1].

According to the study conducted for the United States Department of Health and Human Services and the Agency for Healthcare Research and Quality under the Effective Health Care Program, a patient registry is an organized system that uses observational (non-experimental) research methods based on the collection of standardized data (clinical and other) to assess certain consequences for the population caused by specific diseases, states or impacts, and serves one or more designated scientific, clinical or program-strategic objectives [2].
The term "registry" is defined as the act of recording (or registration) and the record itself [3]. Thus, registries can refer both to the programs collecting and storing data, and to the records created with their use.

The term "patient registry" is conventionally used to distinguish the registration of health information from other records, while there is no single accepted definition at present. The World Health Organization [4] defines registries in medical information systems as "document files containing unified information about individuals, collected systematically or exhaustively for later use with definite purposes".

The National Committee on Vital and Health Statistics [5] defines registries, used to solve a wide range of problems in healthcare and medicine, as "an organized system for collecting, storing, searching, analyzing and distributing information about individuals with a particular disease or state (for example, risk factor)" being the reason for seeking medical help, or about those exposed to the substances (or circumstances) having a known or suspected negative effect on their health. Alternative definitions refer to the patient 
registries, including clinical registries, registries of diseases and long-term effects $[6,7]$.

One of the top technologically developed medical fields is represented by traumatology and orthopedics, hence an importance of developing and implementing effective systems for medical information exchange among the core participants of the medical treatment process. In order to make effective management decisions in this clinical area, taking into account that the lesions of the backbone or large joints are predominant in the nosologic structure [8, 9], it is relevant to compile systematic information on epidemiology of these medical conditions in a specific geographical area, volume and types of surgical interventions, and their remote results. The task can be effectively implemented by creating and maintaining the specialized registry of the patients with spinal and pelvic pathologies. Since the beginning of the 2000s, some regional experience in creating registries of specialized patients was accumulated in Russia. However, they solved merely certain technical problems and were not widely used.

The objective of our study was to come up with a methodology for information exchange among the core healthcare participants in providing medical assistance to traumatology and orthopedics patients based on the development of specialized registries.

\section{Material and methods}

Within the framework of this study, we searched for registries of information, accompanying medical treatment of traumatology and orthopedics patients, in the databases of the Federal Institute of Industrial Property, European Patent Office, and developers' websites. The search depth has been set at 1979 and defined by the date of the earliest discovered information source. The collected material was compiled of patent, scientific and technical information presented in the description of 31 relevant specialized registries. Categorical indicators are presented in the table below in absolute values and in the form of frequencies, expressed in percent.

Table. Patient registries versus their function

\begin{tabular}{|c|c|c|}
\hline $\begin{array}{c}\text { Information } \\
\text { defining registry } \\
\text { function }\end{array}$ & Information consumer & $\begin{array}{c}\text { Number of } \\
\text { registries, } \\
\text { absolute (\%) }\end{array}$ \\
\hline $\begin{array}{c}\text { Information on } \\
\text { conducted } \\
\text { treatment and } \\
\text { diagnostics }\end{array}$ & $\begin{array}{c}\text { Medical organizations, } \\
\text { healthcare management } \\
\text { authorities }\end{array}$ & $22(70,9)$ \\
\hline $\begin{array}{c}\text { Information on } \\
\text { patient } \\
\text { rehabilitation }\end{array}$ & $\begin{array}{c}\text { Healthcare management } \\
\text { authorities, } \\
\text { establishments of } \\
\text { sanatorium and health } \\
\text { resort treatment }\end{array}$ & $2(6,5)$ \\
\hline $\begin{array}{c}\text { Data for } \\
\text { geometric } \\
\text { planning defining } \\
\text { the implant } \\
\text { choice }\end{array}$ & $\begin{array}{c}\text { Medical organizations, } \\
\text { developers, } \\
\text { manufacturers, } \\
\text { procurement services of } \\
\text { medical organizations }\end{array}$ & $7(22,6)$ \\
\hline TOTAL & ran (100) \\
\hline
\end{tabular}

\section{Results}

Analysis and systematization of the structure, flowcharts and functionality of existing traumatology and orthopedics patient registries showed that the products, containing information on various therapeutic and diagnostic parameters (70.9\%), featuring medical treatment process at a clinic level, prevailed. Moreover, each registry was associated with a specific nosologic group (i.e. it was mono-nosologic). It is worth mentioning that there were merely single registries, related to rehabilitation $(6.5 \%)$, which implied the low interest of health officials in the development of that crucial area. It is necessary to single out a separate group of registries, predominantly containing information on implants (22.6\%) used for geometric planning of surgical interventions on the backbone and hip joints (Table).

Among registries, working with the data on ongoing therapeutic and diagnostic activities, there were the products enabling the forecasts for the outcomes of patient surgical treatment - for example, in case of degenerative diseases of the lumbar spine. However, the analyzed registries were closed, i.e. they contained a certain number of the patients and allowed evaluation only on the basis of once obtained measurement results, thus not considering the influence of changing population factors (such as regional differences in biochemical, biophysical and anthropometric parameters).

\section{Discussion}

Patient registries in the growing volume of general and personalized medical information are few, scattered and incompatible with each other and other information systems. Therefore, they require the development of innovative approaches to registering, storing, systematizing and exchanging information within a single function-and-targetoriented registry. Such registries should include information on used medical devices, medications, medical technologies, rehabilitation programs and quality control of the medical treatment. Special attention should be paid to the use of preoperative planning systems, possessing the functionality of a medical information registry and implementing a technological approach to ensuring medical treatment quality, sensu the methodology proposed by A. Donabedian [10]. The resulting possibility of combining specific data contained in various registries developed in the information systems of major participants of the healthcare industry (medical organizations, healthcare management authorities, as well as the manufacturers of medical devices, medications and products for diagnostic services) would significantly improve the quality of medical and other decisions (Figure).

While developing an integrated function-and-targetoriented registry of the patients with spinal and pelvic pathologies, it is necessary to ensure that the effects of the condition of all anatomical and functional body systems on the development of the pathological process, rather than local factors alone, are taken into account. Currently, medical professionals combine biomechanically-induced compensatory changes in the lumbosacral spine of the patients with deforming arthritis of the hip joints into an integrated hip-spine syndrome [11-13]. The need to apply this approach for the spinal and pelvic pathologies would improve the results of the patients' postoperative rehabilitation via timely correction of the hip-spine syndrome development causes in each particular case. 


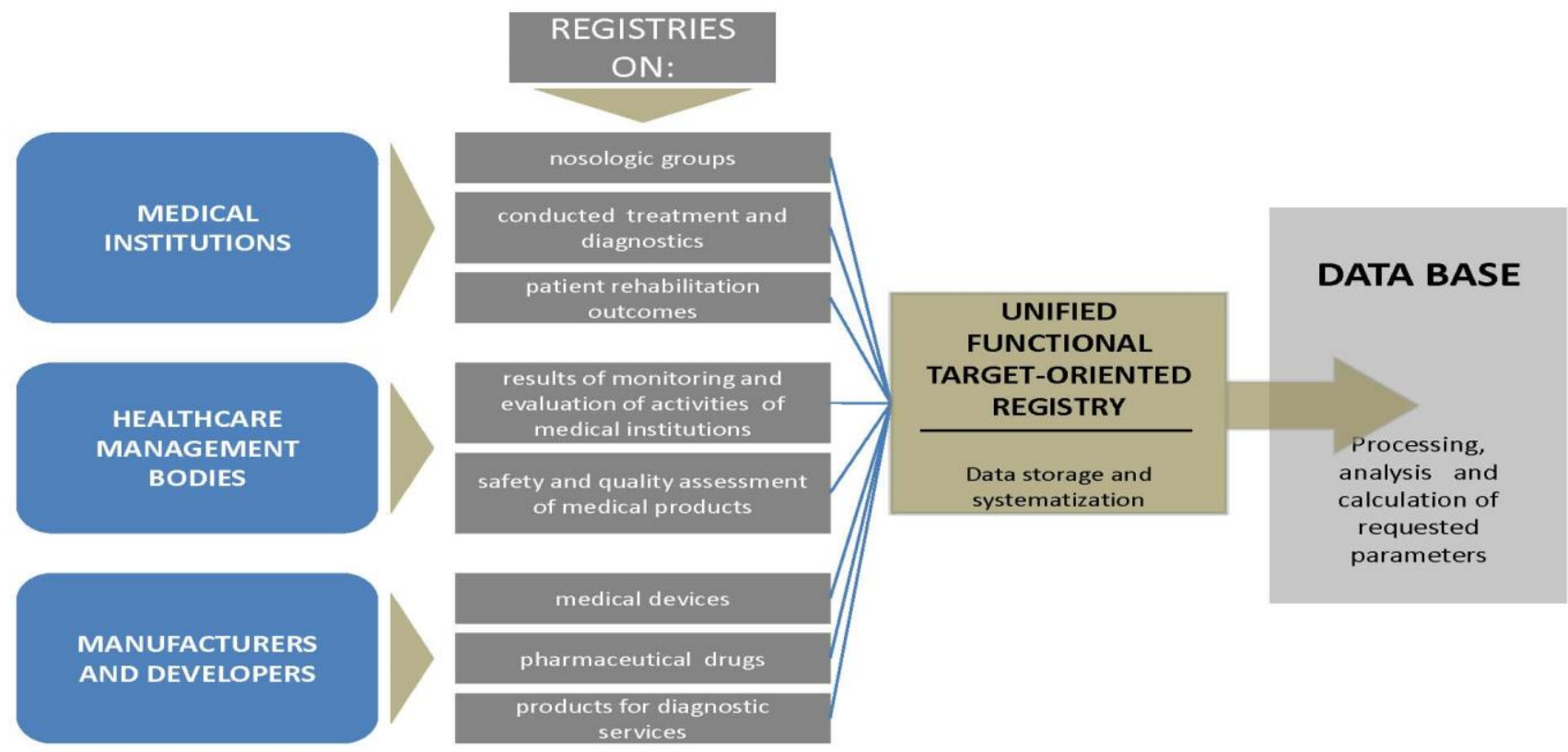

Figure. Schematic diagram featuring the functioning of a specialized medical information registry

In the course of combining available registries into a single function-and-target-oriented registry, it is necessary to consider and adjust their functional features to eliminate potential internal inconsistencies of the data. Such inconsistencies may arise when both directly observable / measured data (let us call them "direct data") and "derived data" are entered into the registry simultaneously. "Derived data" should be understood as those obtained indirectly: e.g. by calculation from "direct data" or empirically (i.e. based on professional experience). If some of the "derived data" can be obtained in some cases indirectly, while in other cases by direct measurement, then there is a risk of internal inconsistency. Such inconsistencies would significantly reduce the forecasting quality of any evaluation (prognostic) model in each particular case. If so, then the decisions made by medical professionals, healthcare authorities, manufacturers and developers of medical devices, as well as other core healthcare participants will not lead to anticipated results. An important technical possibility of the proposed registry should be the function of on-going multidimensional development of the database under construction, which would allow data analysis and processing, along with the calculation of requested parameters, rather than merely storing and organizing the data.

\section{Conclusion}

The proposed traumatology- and orthopedics-related information exchange methodology among the core participants of the healthcare system, defines the feasibility of developing an integrated function-and-target-oriented registry containing a set of data fully characterizing the described process. The implementation of such integrated registry would improve the quality of medical and other decisions that determine an achievement of anticipated healthcare results.

\section{Conflict of interest}

Our study was supported by the Russian Foundation for Advanced Research (contract No. 6/130/2018-2021). 


\section{References}

1. Yagudina RI., Litvinenko MM., Sorokovikov IV. Patient registers: structure, functions, use possibilities. Farmakoehkonomika. Sovremennaya farmakoehkonomika i farmakoehpidemiologiya 2011; 4(4): 3-7.

https://cyberleninka.ru/article/n/registry-patsientov-strukturafunktsii-vozmozhnosti-ispolzovaniya

2. Gliklich RE, Dreyer NA, Leavy MB. Registries for Evaluating Patient Outcomes: A User's Guide [Internet]. 3rd edition. Rockville (MD): Agency for Healthcare Research and Quality (US) 2014; 13(14): 309p.

https://pubmed.ncbi.nlm.nih.gov/24945055/

3. Webster's English Dictionary. http://www.m-w.com. (17.09.2018).

4. Brooke EM. The current and future use of registers in health information systems. Geneva: World Health Organization; 1974. Publication No. 8.

5. National Committee on Vital and Health Statistics, 2012 https://ncvhs.hhs.gov

6. Dokholyan RS, Muhlbaier LH, Falletta JM, et al. Regulatory and ethical considerations for linking clinical and administrative databases. American Heart Journal 2009; 157(6): 971-982.

https://pubmed.ncbi.nlm.nih.gov/19464406/

7. Hammill BG, Hernandez AF, Peterson ED, et al. Linking inpatient clinical registry data to Medicare claims data using indirect identifiers. 2009; 157(6): 995-1000.

https://pubmed.ncbi.nlm.nih.gov/19464409/

8. The Bone and Joint Decade. Global Alliance for Musculoskeletal Health. Key facts from The Global Burden of Disease 2012. http://bjdonline.org/?page $\mathrm{id}=1574 \quad$ (21.09.2018)

9. Woolf $\mathrm{AD}$, Pfleger B. Burden of major musculoskeletal conditions. Bulletin of the World Health Organization 2003; 81(9): 646-56. https://pubmed.ncbi.nlm.nih.gov/14710506/

10. Donabedian A. The definition of quality and approaches to its assessment. In Explorations in quality assessment and monitoring. Ann Arbor, Mich.: Health Administration Press 1980; 1: 95-99. https://psnet.ahrq.gov/issue/definition-qualityand-approaches-its-assessment-vol-1-explorations-qualityassessment-and

11. Wang W, Sun M, Xu Z, et al. The low back pain in patients with hip osteoarthritis: current knowledge on the diagnosis, mechanism and treatment outcome. Ann Joint 2016; 1(9): 1-5. https://doi.org/10.21037/aoj.2016.06.03

12. Devin CJ, Mccullough KA, Morris BJ, et al. Hip-spine Syndrome. Academy of Orthopaedic Surgeons 2012; 20(7): 434-42. https://doi.org/10.5435/JAAOS-20-07-434

13. Matsuyama Y. Hip-spine syndrome: total sagittal alignment of the spine and clinical symptoms in patients with bilateral congenital hip dislocation. Spine 2004; 29: 2432-2437.

http://dx.doi.org/10.1097/o1.brs.0000143671.67779.14

Authors:

Aleksander S. Fedonnikov - PhD, Head of the Department of Technological Innovation in Healthcare and Rehabilitation, Research Institute of Traumatology, Orthopedics and Neurosurgery, ViceChancellor for Science and Research, Saratov State Medical University, Saratov, Russia;

Anna S. Kolesnikova - PhD, Senior Research Scientist, Laboratory of Medical Decision Support Systems, Saratov State University, Saratov, Russia;

Yuliya Yu. Rozhkova - Senior Research Scientist, Department of Technological Innovation in Healthcare and Rehabilitation, Head of the Department of Intellectual Property and Technology Transfer, Research Institute of Traumatology, Orthopedics and Neurosurgery, Saratov State Medical University, Saratov, Russia;

Irina V. Kirillova - PhD, Head of the Laboratory of Medical Decision Support Systems, Saratov State University, Saratov, Russia;
Leonid V. Bessonov - PhD, Principal Research Scientist, Laboratory of Medical Decision Support Systems, Saratov State University, Saratov, Russia;

Vladimir Yu. Ulyanov - DSc, Deputy Head of the Division of Technological Innovation in Healthcare and Rehabilitation, Deputy Director for Science and Innovation at Research Institute of Traumatology, Orthopedics and Neurosurgery, Saratov State Medical University, Saratov, Russia;

Leonid Yu. Kossovich - DSc, President, Saratov State University, Saratov, Russia. 